\title{
COMPARISON OF SOLVOTHERMAL AND IONOTHERMAL METHODS ON CATALYTIC ACTIVITY OF MIL-53 (Fe)
}

\author{
Esra YILMAZ ${ }^{1}$, Emine SERT ${ }^{1,}{ }^{*}$, Ferhan Sami ATALAY ${ }^{1}$ \\ ${ }^{1}$ Department of Chemical Engineering, Faculty of Engineering, Ege University, İzmir, Turkey
}

\begin{abstract}
Iron based MIL-53 (Fe) was synthesized using solvothermal and ionothermal methods. Afterwards, the synthesized materials were sulfated to increase the acidic property. Characterization of the synthesized and sulfated materials were performed using FT-IR, BET, XRD and TGA methods. The sulfated materials were used in the esterification reaction of acetic acid to test the catalytic activity. The effect of synthesis method on the structure of MIL-53 (Fe) and effects of temperature, time and sulfation of samples on the conversion of acetic acid were also studied. Also, reusability of sulfated samples was achieved by washing with pure water. In ionothermal synthesis of iron based metal organic framework, deep eutectic solvent formed when choline chloride and dimethyl urea was used as solvent.
\end{abstract}

Keywords: MOF, MIL-53(Fe), Ionothermal, Solvothermal, Deep eutectic solvents (DES)

\section{INTRODUCTION}

Metal organic frameworks (MOFs) are highly porous materials which are formed by the combination of a metal precursor and salts as the inorganic part and a ligand as the organic part. They have many advantages such as low density, high surface area, tunable pore size, and high porosity. Due to peculiar features, such as unsaturated metal active sites, high surface area, and easily functionalization, its usage as a catalyst is promising.

Iron based metal organic framework, MIL-53(Fe) is formed with infinite chains of trans-corner-shared $\left[\mathrm{FeO}_{4}(\mathrm{OH} / \mathrm{F})_{2}\right]$ or $\left(\mathrm{FeO}_{6}\right)$ octahedral units crosslinked by 1,4 benzenedicarboxylate (BDC) ligands to give a 3D net in which one-dimensional channels run parallel to the inorganic backbone of the structure. Thus, as presented in Figure 1, rhomb-shaped one dimensional channels are formed that run along the axis of the structure [1-3]. The main property of this MOF is that, MIL-53 (Fe) does not have a high surface area. Unlike the other MOFs, it has a flexible structure and it opens its pores only in the presence of guest molecules. Figure 2 shows the open and closed pores of MIL-53 (Fe). Its flexible structure enables the usage of this material in limited application areas especially gas storage and adsorption [2], liquid phase adsorption and separation processes [3], and photocatalytic decolorization of dyes [4]. As far as we know, the catalytic activity of this material has not yet been fully clarified.

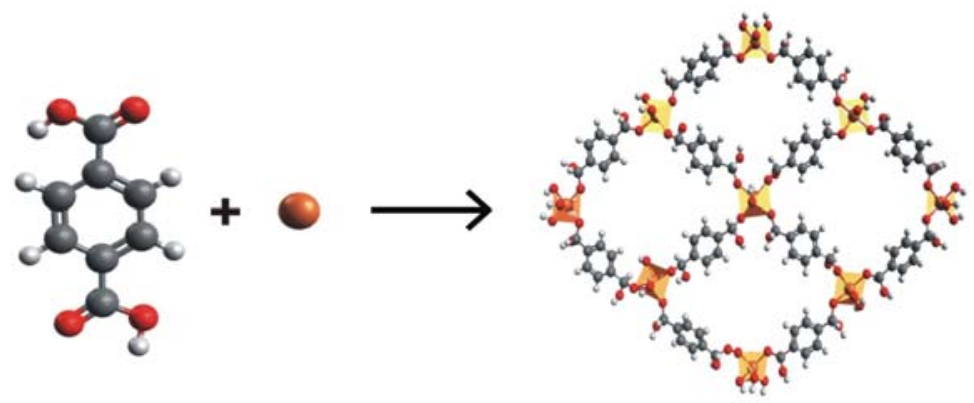

Figure 1. Crystal structure of MIL-53 (Fe) with view along chains of $\mathrm{FeO}_{6}$ octahedra

*Corresponding Author: emine.sert@ege.edu.tr 

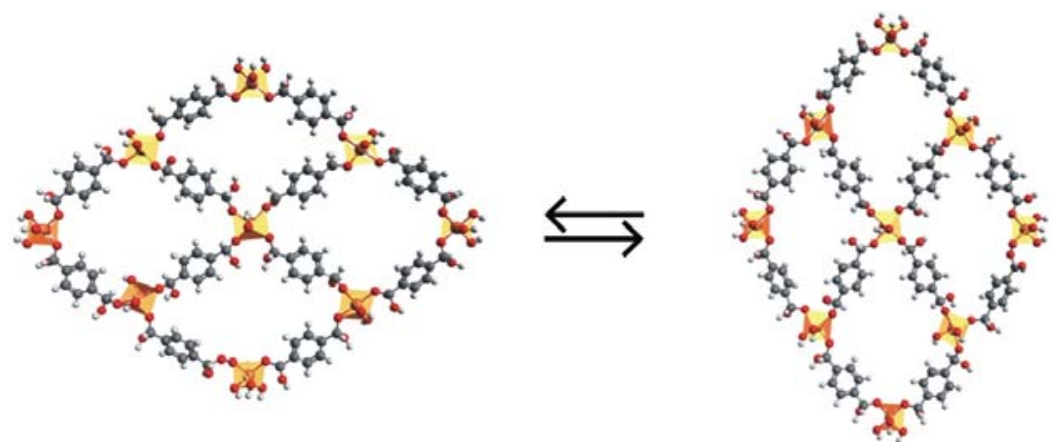

Figure 2. Structure of MIL-53 (Fe) with open and closed pores

In this study, an iron based metal organic framework was synthesized with the solvothermal and ionothermal methods. The solvothermal method is considered a common method for the synthesizing of MOFs. In this method, water or organic solvent is used then the resulting solution is heated in a sealed autoclave under autogenous pressure. One of the disadvantages of this method is that the reaction takes a long time depending upon the MOF of interest and the reaction solvent, reaction temperature, reagent concentrations, and other factors $[5,6]$. The other disadvantage of this method is usage of a solvent which is not preferred due to recent issues about environmental pollution and green chemistry. Therefore, new synthesis methods which includes environmentally friendly solvents have gained importance[7]. Ionic liquids (ILs) are example of these green solvents.

There are a few studies on the synthesizing of MOFs using ILs as a solvent. Tan et al., (2011) studied cadmium based MOF synthesis with the ionothermal method using an ionic liquid (IL) [Emim] $\mathrm{BF}_{4}$ or mixed ILs of $\left[\mathrm{Emim}_{\mathrm{B}} \mathrm{BF}_{4}\right.$ and $[\mathrm{Emim}] \mathrm{Br}$ both as a solvent and template. The thermal and photo luminescent properties were also investigated[8]. Nickerl et al., (2012) synthesized two cationic MOFs using imidazolium salts as linker and copper or zinc as the metal. They concluded these MOFs showed a high selectivity in liquid phase adsorption[9]. Emily et al., (2007) synthesized zeolites and MOFs using the ionothermal and solvothermal methods. In the ionothermal method, ionic liquids were used as a solvent and template (structure directing agent). Then the comparison of the two types of synthesizing methods was performed to view the structural features[10].

Although ILs are environmentally friendly solvents, they have many disadvantages including their high cost of manufacturing, the complex synthesis, purification, and toxicity in nature. Therefore, deep eutectic solvents (DES), a new ionic liquid type, which does not have these disadvantages has emerged. DES can be synthesized with the mixing of two components, one of them is a hydrogen bond donor (HBD) and the other is a hydrogen bond acceptor (HBA). The main properties of these components are being cheap, biodegradable, and renewable. With the simple mixing of these two components using a specified ratio, a eutectic mixture is formed. DES has a melting point that is lower than the individual components. The eutectic mixtures are generally characterized by a very large depression of freezing point $[7,11,12]$. In literature MIL-53 $(\mathrm{Fe})$ synthesis using the ionothermal method including the use of ILs or DES has not been demonstrated.

Esters are formed by acids and alcohol. Since the esterification reaction of acetic acid with butanol is reversible and is a slow reaction it requires an acidic catalyst to start the reaction because of the proton requirement.

In this study, the synthesis method is a parameter that affects the structure and applicability of MIL-53 $(\mathrm{Fe})$. Therefore, an iron based metal organic framework was synthesized using the solvothermal and ionothermal methods. Because of the highly toxic and harmful solvents used the solvothermal method is not preferred, and the search for green solvents is a new trend. Therefore, in this study a deep eutectic solvent was selected as a green solvent in the synthesis of MIL-53 (Fe). 


\section{MATERIALS AND METHOD}

\section{a. Materials}

Terephthalic acid (TPA, 99\%) and $\mathrm{FeCl}_{3} .6 \mathrm{H}_{2} \mathrm{O}$ (99\%) were purchased from ABCR, N,Ndimethylformamide (DMF, 99.8\%), the hydrofluoric acid (HF, 48\%), butanol, and acetic acid were purchased from MERCK. All the chemicals in this study were used without further purification.

\section{b. Synthesis and sulfation of MIL-53 (Fe)}

In this study, MIL-53 (Fe) was synthesized using the solvothermal and ionothermal methods. The schematic representation of the synthesized samples is given in Figure 3.

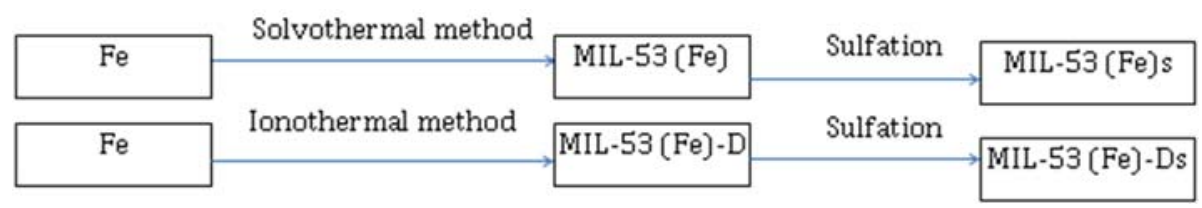

Figure 3. Experimental plan of synthesising and sulfation of MOFs

\section{Synthesis of MIL-53 (Fe) by solvothermal method}

The solvothermal method is considered a common method for the synthesizing of MOFs. The synthesis of MIL-53(Fe) using the solvothermal method has been reported in literature [13]. In this method, an equimolar of iron chloride $\left(\mathrm{FeCl}_{3} \cdot 6 \mathrm{H}_{2} \mathrm{O}, 1 \mathrm{mmol}\right)$, terephthalic acid (TPA, $\left.1 \mathrm{mmol}\right)$, and HF (1 mmol) were mixed in a solvent of N,N-dimethylformamide (DMF, $5 \mathrm{~mL}$ ) and placed in a Teflon lined stainless steel autoclave at $150{ }^{\circ} \mathrm{C}$ for 3 days for the synthesis. The synthesized yellow MIL-53(Fe) solid was produced. The product was separated and the remaining DMF was removed by extraction with methanol. The sample was dried at $100^{\circ} \mathrm{C}$.

\section{Synthesis of MIL-53 (Fe) by ionothermal method}

In the ionothermal synthesis of MIL-53(Fe) a deep eutectic solvent formed using $\mathrm{ChCl}$ and urea was used. The $\mathrm{ChCl}$ and Urea ratio at the eutectic point was $1: 2 . \mathrm{FeCl}_{3} \cdot 6 \mathrm{H}_{2} \mathrm{O}, \mathrm{H}_{2} \mathrm{BDC}$ and $\mathrm{HBA}$, and HBD of DES (ChCl-Urea) were mixed with a molar ratio of 1:0.5:7:14. The mixture is then heated above the eutectic temperature and then an ultrasonic generator (VCX 500, SONICS, $175 \mathrm{~W}$ ) is used for $30 \mathrm{~min}$ and after that the mixture is heated at $110^{\circ} \mathrm{C}$ for 3 days. After 3 days the mixture is cooled to room temperature, the solid is recovered by filtration and then washed several times with hot ethanol for purification. Finally, the solid powder is activated at $423 \mathrm{~K}$ for $12 \mathrm{~h}$. This material was designated as MIL-53-(Fe)-D.

The obtained MIL-53 (Fe) and MIL-53 (Fe)-D were sulfated in order to rise the acidity [14] according to the procedure. Sulfuric acid and trifluoromethanesulfonic anhydride (triflic anhydride, $\mathrm{Tf}_{2} \mathrm{O}$ ) were added to the solvent, nitromethane $\left(\mathrm{CH}_{3} \mathrm{NO}_{2}\right)$ in the molar ratio of MOF-incorporated terephthalate $/ \mathrm{H}_{2} \mathrm{SO}_{4} / \mathrm{Tf}_{2} \mathrm{O}=1: 1: 1.5$ and stirred at room temperature for $1 \mathrm{~h}$. Then, washing with an ultrapure water and acetone procedure was applied, then soaked in ethanol for $24 \mathrm{~h}$ at $343 \mathrm{~K}$, and held at $433 \mathrm{~K}$. The sulfated samples were designated with subscript s, MIL-53 (Fe)s, and MIL-53 (Fe)-Ds.

\section{c. Characterization of synthesized MOFs}

The X-ray powder diffraction patterns of the MOFs were obtained using a Rigaku Ultima-IV diffractometer. The effect of the synthesis method and the effect of sulfation on the crystallinity of the synthesized materials were studied using XRD analysis. 
The measurement of the surface area and adsorption isotherm of nitrogen on the MOFs was obtained at $77 \mathrm{~K}$ using a Micromeritics Gemini - 2380 apparatus. Before the nitrogen adsorption was accomplished, the humidity content in the MOFs pores was evacuated for $4 \mathrm{~h}$ at $150^{\circ} \mathrm{C}$ to remove the water molecules from the pores of the MOFs. The specific surface area values of the MOF were calculated using the Brunauer-Emmett-Teller (BET) method and the Langmuir method using the adsorption data of the nitrogen adsorption isotherm.

The thermal stability of the MOFs was investigated using thermal gravimetric analysis (TGA), with a Perkin Elmer Pyris 1 thermal analyzer with a range between $30{ }^{\circ} \mathrm{C}$ and $500{ }^{\circ} \mathrm{C}$ with a heating rate of 5 ${ }^{\circ} \mathrm{C} / \mathrm{min}$.

The ATR-Fourier transform infrared (FT-IR) spectrum was determined using an FT-IR spectrum 100 with a range of $650-4000 \mathrm{~cm}^{-1}$. Scanning electron microscopy (SEM) images were recorded on a FEI Quanta $400 \mathrm{~F}$ scanning electron microscope operating at $20 \mathrm{kV}$. The structural changes due to the synthesis method and sulfation were characterized using FT-IR analysis.

To understand whether the materials gain acidic property, the N-butylamine titration method was carried out for the raw and sulfated MOFs. A 0.05 gram of the MOF was suspended in $10 \mathrm{~mL}$ of acetonitrile and mixed for 3 hours. Then, the suspension was titrated with $0.1 \mathrm{~N}$ n-butylamine in acetonitrile.

\section{d. Catalytic Activity Measurement}

The catalytic activities of all materials, MIL-53 (Fe), MIL 53 (Fe)-D, MIL-53 (Fe)s, and MIL-53 (Fe)Ds were tested in the esterification of acetic acid with butanol. Acetic acid and butanol were fed to the batch reactor equipped with a condenser to prevent loss of material during the experiment. An electrical heater and temperature controller was used to produce the reaction temperature and to control the reaction temperature, respectively. The reaction mixture was stirred at $500 \mathrm{rpm}$ to prevent concentration gradients across the reaction mixture. After the reactants reached the experimental temperature, the catalyst was added. After the reaction time was completed, liquid samples were taken for analysis. The experimental program is given in Table 1.

The analyses of the samples were performed using an Agilent 7890A gas chromatograph with hydrogen being used as the carrier gas. The temperature program of the gas chromatographic analysis is given as follows: waiting $3 \mathrm{~min}$ at $60{ }^{\circ} \mathrm{C}$; heating from 60 to $180^{\circ} \mathrm{C}$ at a rate of $5^{\circ} \mathrm{C} / \mathrm{min}$; and waiting for $3 \mathrm{~min}$ at $180^{\circ} \mathrm{C}$. From gas the chromatographic analysis, the conversion of the limiting reactant (acetic acid) was calculated.

Table 1. The experimental schedule

\begin{tabular}{|c|c|c|c|c|c|}
\hline & Sample & $T(K)$ & $\begin{array}{l}\text { Butanol/Acetic } \\
\text { acid molar ratio }\end{array}$ & $\begin{array}{c}\text { Catalyst } \\
\text { Loading (wt\%) }\end{array}$ & Time (min) \\
\hline \multirow{3}{*}{$\begin{array}{c}\text { Effect of } \\
\text { Temperature }\end{array}$} & MIL-53 (Fe)s MIL-53 (Fe)-Ds & 353 & 1 & 6 & 360 \\
\hline & MIL-53 (Fe)s, MIL-53 (Fe)-Ds & 358 & 1 & 6 & 360 \\
\hline & MIL-53 (Fe)s, MIL-53 (Fe)-Ds & 363 & 1 & 6 & 360 \\
\hline \multirow{2}{*}{$\begin{array}{l}\text { Effect of } \\
\text { sulfation }\end{array}$} & MIL-53 (Fe), MIL-53 (Fe)-D & 363 & 1 & 6 & $15-360$ \\
\hline & MIL-53 (Fe)s, MIL-53 (Fe)-Ds & 363 & 1 & 6 & $15-360$ \\
\hline \multirow[t]{3}{*}{ Reusability } & MIL-53 (Fe)s MIL-53 (Fe)-Ds & 363 & 1 & 6 & 360 \\
\hline & $\begin{array}{l}\text { MIL-53 (Fe)s -Second use, MIL-53 } \\
\text { (Fe)-Ds-Second use }\end{array}$ & 363 & 1 & 6 & 360 \\
\hline & $\begin{array}{l}\text { MIL-53 (Fe)s - Third use, MIL-53 } \\
\text { (Fe)-Ds- Third use }\end{array}$ & 363 & 1 & 6 & 360 \\
\hline \multirow[t]{2}{*}{ Hot Filtration } & MIL-53 (Fe) MIL-53 (Fe)-D & 363 & 1 & 6 & $15-360$ \\
\hline & MIL-53 (Fe)s, MIL-53 (Fe)-Ds & 363 & 1 & 6 & $15-360$ \\
\hline
\end{tabular}




\section{RESULTS AND DISCUSSION}

\section{e. Characterization Results}

\section{$\underline{\text { Synthesized and sulfated MIL-53 (Fe) }}$}

The textural and structural properties of metal organic frameworks based on Fe were obtained. Also, the effect of sulfation and the synthesis method were studied. Figure 4 shows the crystal structure of the synthesized materials. In the pattern of the MIL-53, the main diffraction peaks appearing at $2 \Theta$ are $9.24,11.7,16.66,18.24,18.58,22,25.52,27.32,29.8,30.28$, and 36.18 which are identical to those reported for the MIL-53 phase $[1,15]$. As shown in Figure 4 the main diffraction peaks reserved after sulfation, the peaks became much steeper, and the crystal sizes became smaller. Similar results were obtained for sulfation of other metal organic frameworks [14].

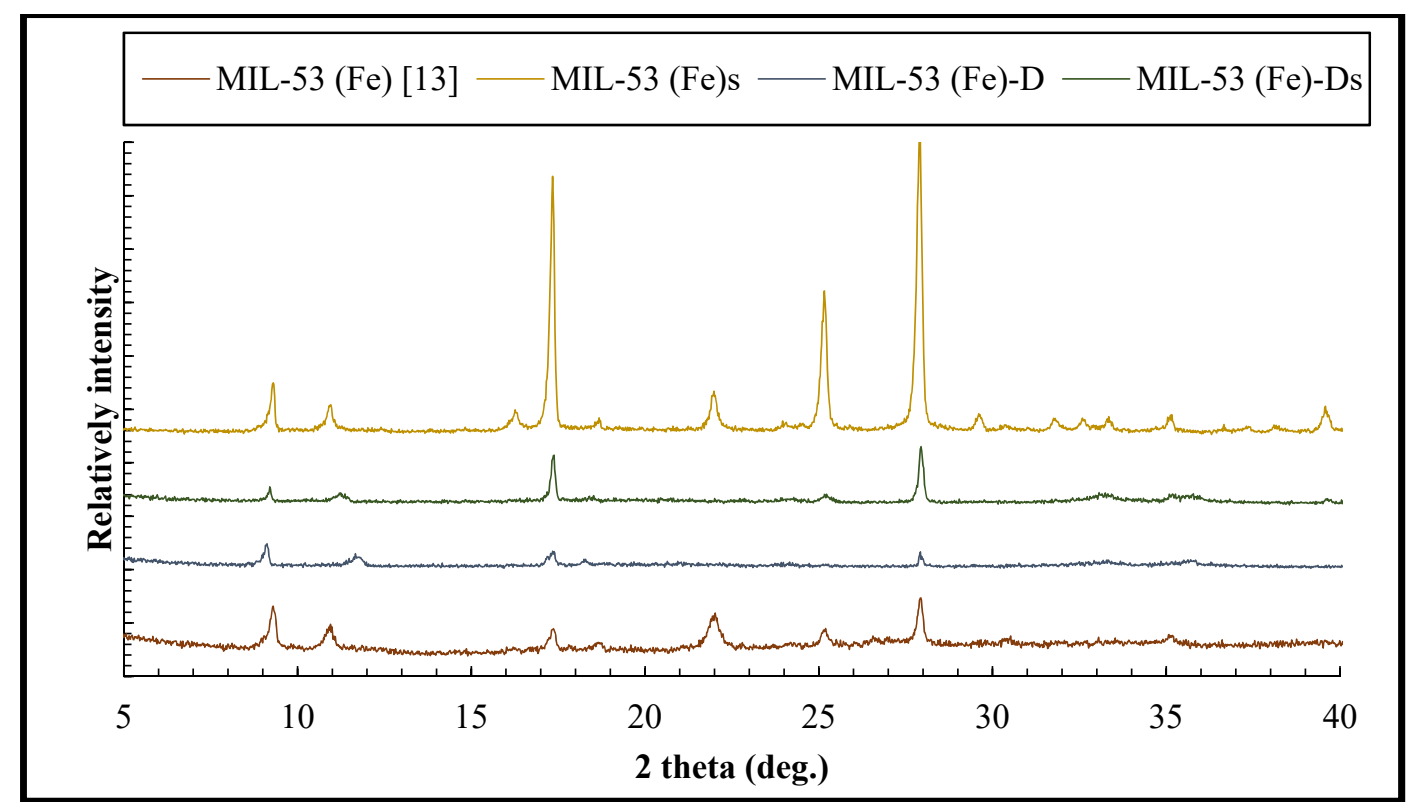

Figure 4. XRD pattern of MIL-53(Fe), D-MIL-53(Fe), MIL-53(Fe)s and D-MIL-53(Fe)s

In the solvothermal method, solvents are used to synthesize the metal organic framework. Taking into account the environmental effect, the ionothermal method was applied to produce the MOF. When using the ionothermal method, MIL-53 is synthesized using a deep eutectic solvent (ChCl-urea). As shown in the analysis, the crystal structures are almost the same for samples obtained using the solvothermal and ionothermal method. The only difference is that the peaks at $2 \Theta$ of $22,25.52$, and 30.28 disappeared in the XRD pattern of MIL-53 synthesized using the ionothermal method. In the ionothermal synthesis, the crystal sizes were much greater than that of the solvothermal method.

The specific surface area was evaluated using the Brunauer-Emmett-Teller (BET) and Langmuir methods for all synthesized and sulfated samples (Table 2). Due to the closed pores for $\mathrm{N}_{2}$ at $77 \mathrm{~K}$, the flexible MIL-53(Fe) exhibits no accessible porosity [16]. MIL-53(Fe) produced using eutectic solvents give less surface area and pore volume. Ionothermal synthesis gave less surface area, but the framework preserved its porous structure. Sulfation reduced the surface area and pore volume for both the MIL-53 (Fe) and MIL-53 (Fe)-D samples. 
Table 2. BET analysis results of MIL-53 (Fe)

\begin{tabular}{|l|c|c|c|c|}
\hline & $\begin{array}{c}\text { BET Surface } \\
\text { Area, } \mathbf{~ m}^{\mathbf{2}} \mathbf{/ g}\end{array}$ & $\begin{array}{c}\text { Langmuir Surface } \\
\text { Area, } \mathbf{~ m}^{\mathbf{2}} \mathbf{g}\end{array}$ & $\begin{array}{c}\text { Pore Volume } \\
\mathbf{c m}^{\mathbf{3}} / \mathbf{g}\end{array}$ & $\begin{array}{c}\text { Adsorption } \\
\text { Average Pore } \\
\text { Width, } \mathbf{\AA}\end{array}$ \\
\hline MIL-53 (Fe) [13] & 23.15 & 33.05 & 0.056 & 98.13 \\
\hline MIL-53 (Fe)s & 12.13 & 17.32 & 0.021 & 70.94 \\
\hline MIL-53-D & 16.74 & 23.38 & 0.039 & 93.015 \\
\hline MIL-53-Ds & 12.1 & 16.25 & 0.018 & 63 \\
\hline
\end{tabular}

The TGA profile shows that the MIL-53(Fe) is stable up to $270{ }^{\circ} \mathrm{C}$ (Figure 5) and a $3 \%$ weight loss between 50 and $100{ }^{\circ} \mathrm{C}$ results from the evaporation of water. The weight loss that occurred between 270 and $400{ }^{\circ} \mathrm{C}$ may be the result of framework decomposition[1]. For the sulfated samples, degradation of the MOFs begins at lower temperatures. The TGA profile shows a typical weight loss pattern for the MIL-53(Fe)-D and the complete degradation of this sample starts around $300{ }^{\circ} \mathrm{C}$ and by $400{ }^{\circ} \mathrm{C}$ the degradation is completed. MIL-53 (Fe)-D gave less thermal stability than MIL-53 (Fe). Ionothermal synthesis can be improved using different deep eutectic solvents also, sulfation reduced the thermal stability for both MIL-53 (Fe) and MIL-53 (Fe)-D samples.

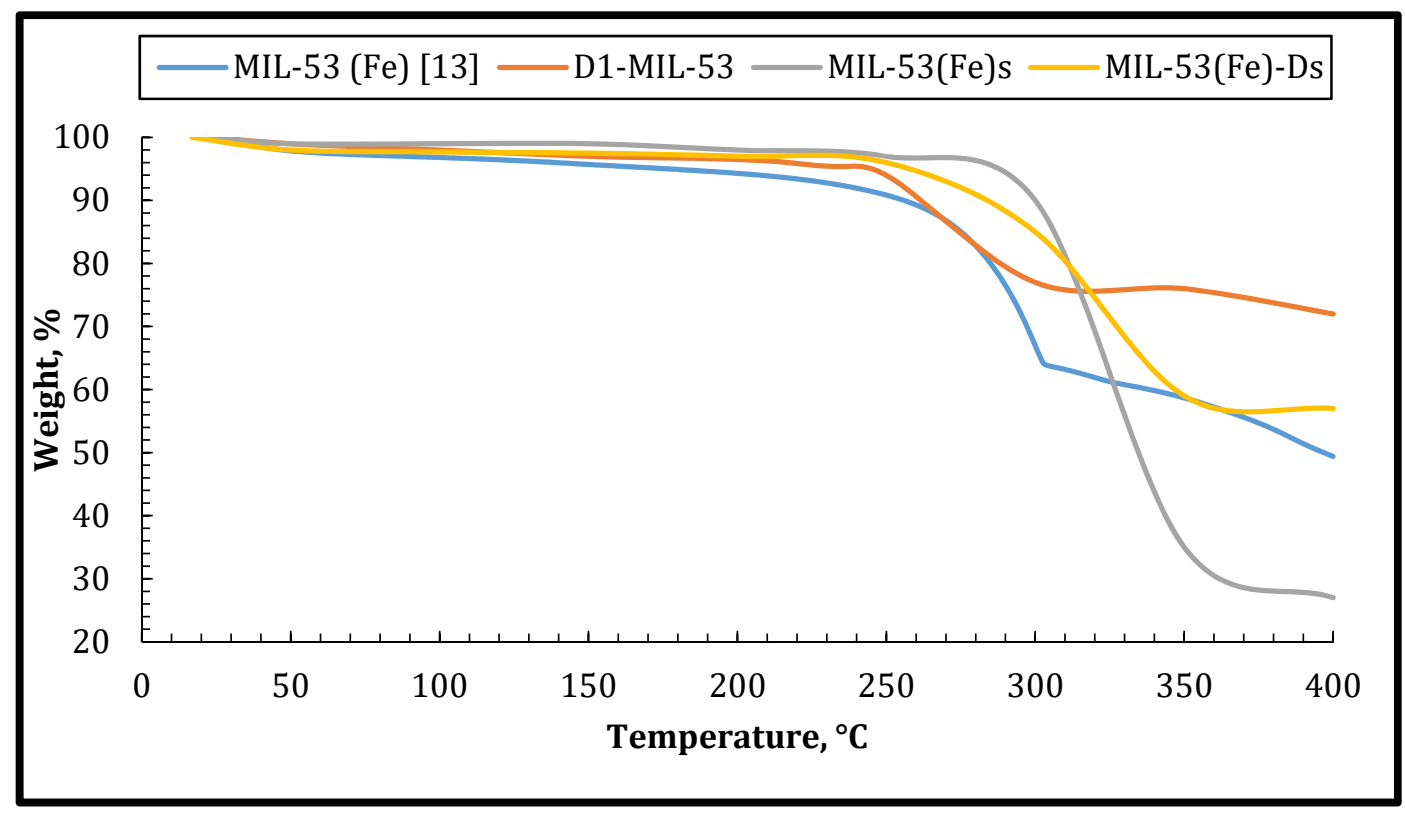

Figure 5. TGA profile MIL-53(Fe), D-MIL-53(Fe), MIL-53(Fe)s and D-MIL-53(Fe)s

According to the FT-IR spectrum of MIL-53(Fe) (Figure 6), the strong bonds between 1700 and 1400 $\mathrm{cm}^{-1}$ correspond to O-C-O vibrations. This is proof of the presence of dicarboxylate within the MIL$53(\mathrm{Fe})$. The bonds at 1020 and $750 \mathrm{~cm}^{-1}$ can be attributed to the vibration of the aromatic ring (benzene). Goesten et al. mentioned the sulfoxy acid stretching's which are shown in the $1550-950$ $\mathrm{cm}^{-1}$ region.[14] Therefore, the peaks at 1382 and $941 \mathrm{~cm}^{-1}$ can be attributed to the sulfoxy acid stretching's for sulfated MIL-53(Fe).Some functional groups disappeared in the ionothermal synthesis of the iron based metal organic framework. 
Yılmaz et al. / Anadolu Univ. J. of Sci. and Technology A - Appl. Sci. and Eng. 18 (5) - 2017

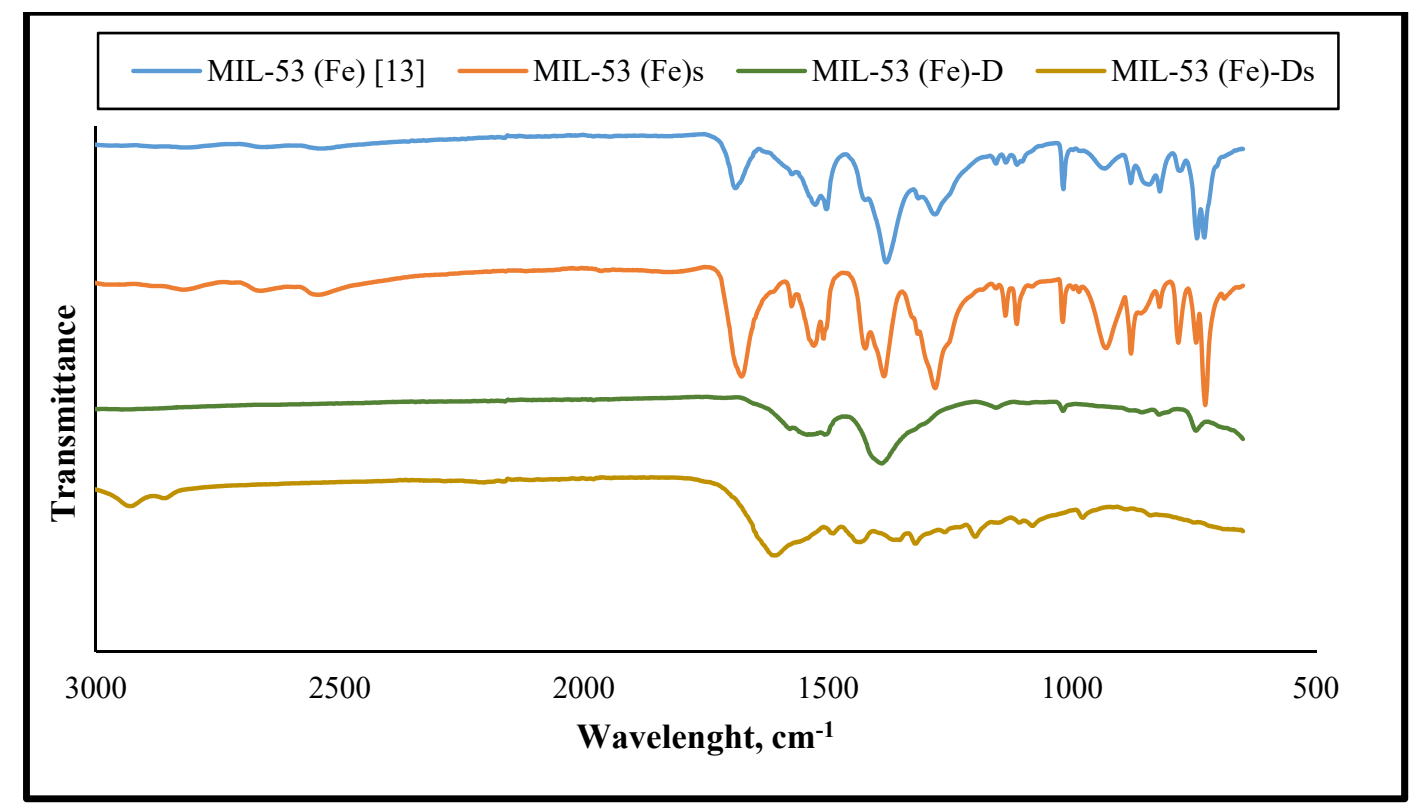

Figure 6. FT-IR spectrum of MIL-53(Fe), D-MIL-53(Fe), MIL-53(Fe)s and D-MIL-53(Fe)s

The surface acidity test for raw and sulfated MOFs was performed using the N-butylamine titration method. Figure 7 shows the titration results of the MOFs. According to the results, acidity increases with sulfation. The initial electrode potential values (Ei) increased from 150 to 395 after sulfation for MIL-53 (Fe). MIL-53 (Fe)-D gave less acidity when compared to MIL-53 (Fe) due to the structural difference. Also, sulfation didn't affect the acidity of the ionothermally synthesized iron based metal organic framework.

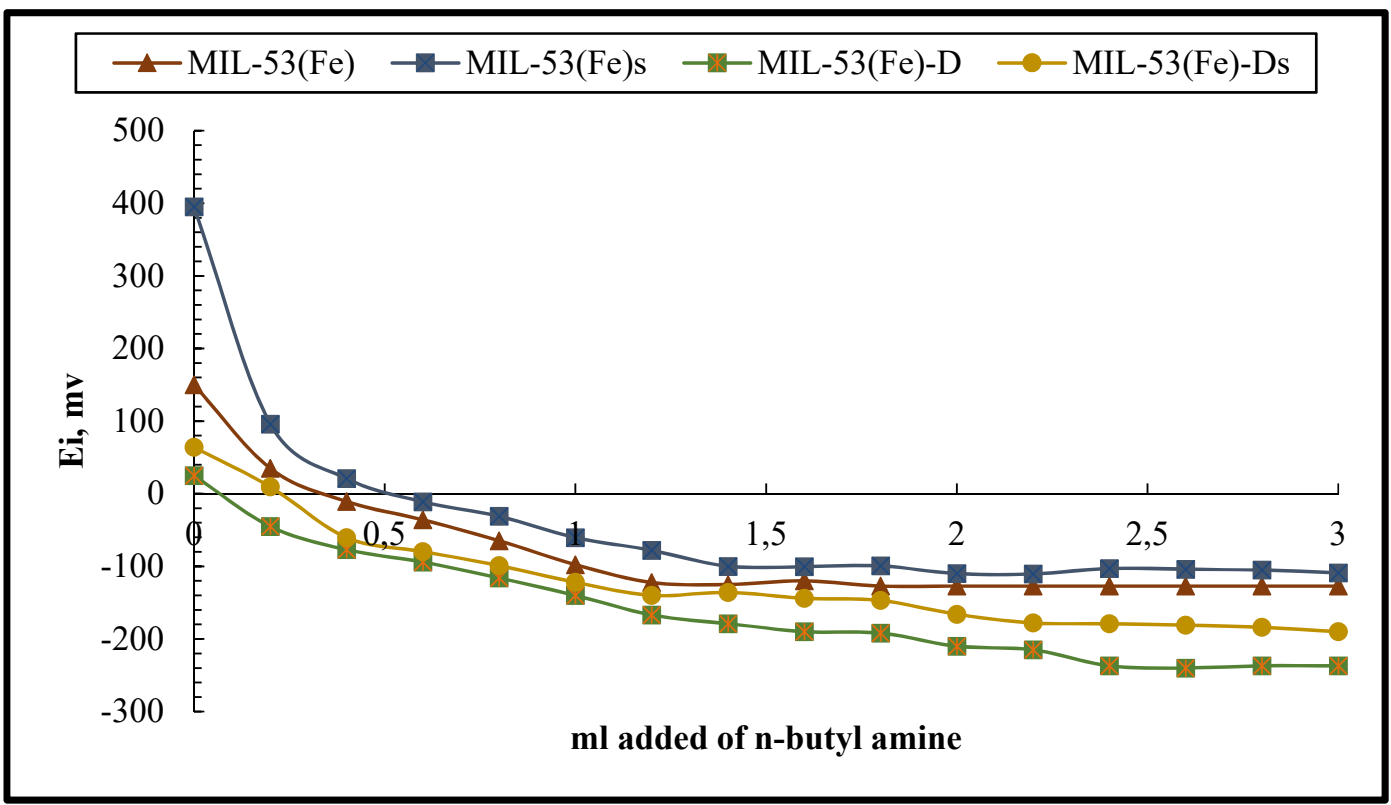

Figure 7. Potentiometric titration of n-butylamine in acetonitrile for MIL-53(Fe), D-MIL-53(Fe), MIL-53(Fe)s and D-MIL-53(Fe)s 


\section{f. Catalytic Activity}

Esterification of acetic acid with butanol catalyzed using synthesized and sulfated materials were carried out.

\section{Effect of the synthesis method;}

Firstly, the effect of the synthesis method on the catalytic activities of iron based metal organic frameworks was studied. The results are given in Table 3. Experiments were performed at a butanol/acetic acid molar ratio of 1 , catalyst loading of $6 \mathrm{wt} \%$, and temperatures of 353,358 , and 363 K. A $75.7 \%$ of acetic acid conversion was achieved using MIL-53 (Fe)s as a catalyst, $45.76 \%$ of acetic acid conversion was achieved for esterification of acetic acid with butanol catalyzed using MIL-53 (Fe)-Ds with the same conditions. Similar results were observed at temperatures of 358 and $363 \mathrm{~K}$. So, the solvothermal method gives a higher catalytic activity due to the higher surface area and acidity.

Table 3. Effect of synthesis method on the conversion of acetic acid

\begin{tabular}{|l|c|c|c|c|c|}
\hline \multicolumn{1}{|c|}{ Sample } & T (K) & $\begin{array}{c}\text { Butanol/Acetic acid } \\
\text { molar ratio }\end{array}$ & $\begin{array}{c}\text { Catalyst } \\
\text { Loading (wt\%) }\end{array}$ & Time (min) & $\boldsymbol{x}$ (\%) \\
\hline MIL-53 (Fe)s & 353 & 1 & 6 & 360 & 75.8 \\
\hline MIL-53 (Fe)-Ds & 353 & 1 & 6 & 360 & 45.8 \\
\hline MIL-53 (Fe)s & 358 & 1 & 6 & 360 & 79.1 \\
\hline MIL-53 (Fe)-Ds & 358 & 1 & 6 & 360 & 52.0 \\
\hline MIL-53 (Fe)s & 363 & 1 & 6 & 360 & 84.8 \\
\hline MIL-53 (Fe)-Ds & 363 & 1 & 6 & 360 & 53.5 \\
\hline
\end{tabular}

\section{Effect of sulfation;}

To understand the importance of the acidic property of a catalyst used in the esterification reaction, the sulfated and non - sulfated materials were also tested. Sulfation increased the acetic acid conversion from $36 \%$ to $53.6 \%$ for MIL-53 (Fe)-D and $45.4 \%$ to $84.8 \%$ for MIL-53 (Fe)-Ds. Sulfation increased the surface acidity of the samples, and as such increased the catalytic activity of the metal organic frameworks (Figure 8).



Figure 8. Sulfation effect on esterification of acetic acid 
Reusability; In addition, reusability of the catalysts was studied. After the experiment was completed, catalysts were washed and activated, then reused. The experiments were carried out at $363 \mathrm{~K}, 6 \mathrm{wt} \%$ of catalyst loading, 1:1 acid alcohol molar ratio, and $500 \mathrm{rpm}$. The used catalysts were filtered from the reaction mixture then they were used again in the same conditions. The results are shown in Figure 9. Results proved that the synthesized sampled preserved the catalytic activities. It can be concluded that from this result, that this material is effective and reusable for liquid phase esterification reactions and could be reused without a significant degradation in catalytic activity. According to this result, MOFs are effective and reusable for liquid phase esterification reactions and could be reused without a significant degradation in catalytic activity.



Figure 9. Reusability of sulfated MOFs

Hot filtration; To observe catalysts leaching, catalysts were filtered after 1 hour, and the experiment continued up to 6 hours, the conversions of acetic acid was obtained in the absence of a catalyst. The results are shown in Figure 10. After the catalyst was filtered, conversion values remained constant, so, it can be concluded that there was no catalyst leaching.

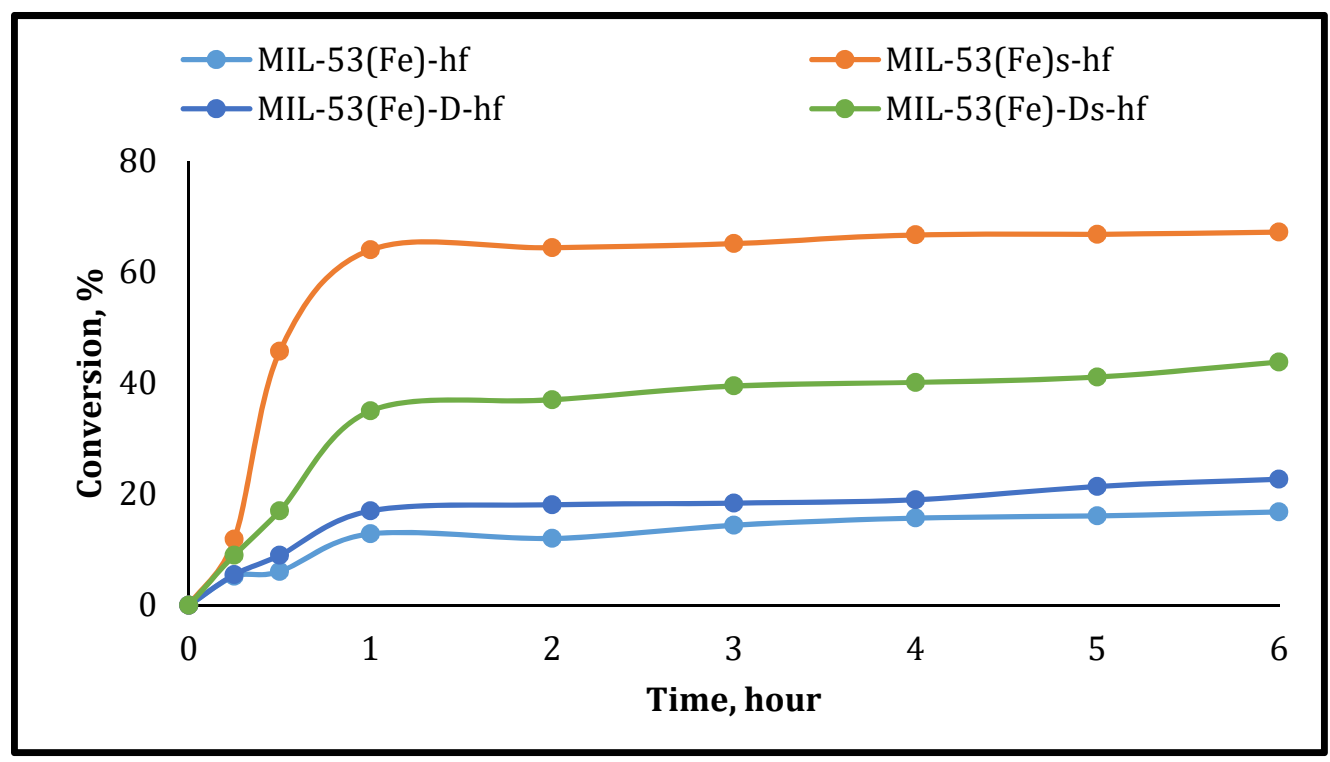

Figure 10. Hot filtration results 


\section{CONCLUSION}

In this study, an iron based metal organic framework was synthesized using solvothermal and ionothermal methods. In ionothermal synthesis of this material, Deep eutectic solvent (DES obtained by simple mixing of Choline Cloride and Dimethyl urea) was used as solvents. DES can be synthesized by mixing of two components, one of them is hydrogen bond donor (HBD) and the other is hydrogen bond acceptor (HBA). Then these samples were sulfated to increase their acidities. Characterization of synthesized and sulfated material was also determined by BET, XRD, TGA and FT-IR methods. According to the characterization results, the crystal structures are almost the same for samples obtained using the solvothermal and ionothermal method. Ionothermal synthesis gave less surface area, but the framework preserved its porous structure. Sulfation reduced the surface area and pore volume for both the MIL-53 (Fe) and MIL-53 (Fe)-D samples. For the sulfated samples, degradation of the MOFs begins at lower temperatures. MIL-53 (Fe)-D gave less thermal stability than MIL-53 (Fe). Sulfation reduced the thermal stability for both MIL-53 (Fe) and MIL-53 (Fe)-D samples. Then the effects of the synthesis method and sulfation were studied in the esterification of acetic acid with butanol. It can be seen from the results acidity increases with sulfation. According to the experiments, sulfation increased the catalytic activity significantly and, the solvothermal method resulted in a highly catalytically active metal organic framework.

\section{ACKNOWLEDGEMENT}

This study was supported by TUBITAK (114M846), Ege University 15MÜH002 and EBILLTEM 2015/BILL/019 scientific research projects.

\section{REFERENCES}

[1] Millange F, Guillou N, Medina ME. Férey G, Carlin-Sinclair A, Golden KM, et al., Selective sorption of organic molecules by the flexible porous hybrid metal-organic framework MIL-53(Fe) controlled by various host-guest interactions, Chem Mater 2010; 22: 4237-4245.

[2] Llewellyn PL, Horcajada P, Maurin G, Devic T, Rosenbach N, Bourrelly S, et al., Complex adsorption of short linear alkanes in the flexible metal-organic-framework MIL-53(Fe), J Am Chem Soc 2009; 131: 13002-13008.

[3] Osta RE, Carlin-Sinclair A, Guillou N, Walton RI, Vermoortele F, Maes M, et al., Liquid-phase adsorption and separation of xylene isomers by the flexible porous metal-organic framework MIL53(Fe), Chem Mater 2012; 24: 2781-2791.

[4] Du JJ, Yuan YP, Sun JX, Peng FM, Jiang X, Qiu LG, et al., New photocatalysts based on MIL-53 metal-organic frameworks for the decolorization of methylene blue dye, J. Hazard. Mater. 2011, $190945-951$.

[5] Lee YR, Kim J, Ahn WS, Synthesis of metal-organic frameworks: A mini review, Korean J Chem Eng 2013; 30:1667-1680.

[6] Jhung SH, Lee,JH Yoon,JW, Serre C, Férey G, Chang JS, Microwave synthesis of chromium terephthalate MIL-101 and its benzene sorption ability, Adv Mater 2007; 19: 121-124.

[7] Zhang Q, De Oliveira Vigier K, Royer S, Jérôme F, Deep eutectic solvents: syntheses, properties and applications, Chem Soc Rev 2012; 41: 7108. 
[8] Tan B, Xie ZL, Huang XY, Xiao XR, Ionothermal synthesis, crystal structure, and properties of an anionic two-dimensional cadmium metal organic framework based on paddle wheel-like cluster, Inorg Chem Commun 2011; 14: 1001-1003.

[9] Nickerl G, Notzon A, Heitbaum M, Senkovska I, Glorius F, Kaskel S, Selective Adsorption Properties of Cationic Metal - Organic Frameworks Based on Imidazolic Linker, Cryst Growth Des 2013; 13: 198-203.

[10] Parnham ER, Morris RE, Ionothermal synthesis of zeolites, metal-organic frameworks, and inorganic-organic hybrids, Acc Chem Res 2007; 40: 1005-1013.

[11] Yusof R, Abdulmalek E, Sirat K, Rahman MBA, Tetrabutylammonium bromide (TBABr)-Based deep eutectic solvents (DESs) and their physical properties, Molecules 2014; 19: 8011-8026.

[12] Abbott AP, Boothby D, Capper G, Davies DL, Rasheed RK, Deep Eutectic Solvents formed between choline chloride and carboxylic acids: Versatile alternatives to ionic liquids, J Am Chem Soc 2004; 126: 9142-9147.

[13] Yilmaz E, Sert E, Atalay FS, Characterization of a metal organic framework: MIL-53(Fe) Synthesis and adsorption mechanisms of methyl red onto MIL-53 ( Fe ), J Taiwan Ins Chem Engineers 2016; 65: 323-330.

[14] Goesten MG, Juan-Alcañiz J, Ramos-Fernandez EV, Sai Sankar Gupta KB, Stavitski E, Van Bekkum H, et al., Sulfation of metal-organic frameworks: Opportunities for acid catalysis and proton conductivity, J Catal 2011; 281: 177-187.

[15] Combarieu GD, Morcrette M, Millange F, Guillou N, Cabana J, Grey CP, et al., Influence of the Benzoquinone sorption on the structure and electrochemical performance of the MIL-53 (Fe) hybrid porous material in a lithium-ion battery, Chem Mater 2009; 21: 1602-1611.

[16] Xie L, Liu D, Huang H, Yang Q, Zhong C, Efficient capture of nitrobenzene from waste water using metal-organic frameworks, Chem Eng J 2014; 246: 142-149. 